\title{
Quantitative assessment of aggregate segregation of hardened self compacted concrete based on 2D image analysis
}

\author{
Jerzy Wawrzeńczyk ${ }^{1}$, Agnieszka Molendowska ${ }^{2}$, Adam Kłak ${ }^{3}$ \\ Faculty of Civil Engineering and Architecture, Kielce University of Technology, Kielce, Poland \\ E-mail:2agam@tu.kielce.pl (corresponding author)
}

\begin{abstract}
Self-compacting concrete developed as a material that does not need vibration for compaction has been increasingly being used in routine practice. Successful application of self-compacting concrete (SCC) is difficult to achieve due to increased flowability of the concrete mixture. Segregation of aggregate is one of the major problems during construction and ultimately influences the strength and durability of SCC. A fresh self-compacting concrete with poor segregation resistance can lead to a nonuniform distribution of coarse aggregates in the concrete volume, contributing to blockage of concrete flow, and nonuniform mechanical properties and durability at the hardened concrete. The article presents the unique method for quantitative assessment of aggregate segregation in hardened self-compacted concrete. A digital image analysis procedure using original lighting microscope equipment has been placed to investigate the concrete segregation behavior. The photographs of concrete specimen surfaces were taken to calculate measurements of aggregate volume in concrete. The research results showed that the originally developed attachment and unique aggregate segregation assessment method are useful in laboratory tests and could be used in the on-site application.
\end{abstract}

Keywords: self-compacted concrete, aggregate segregation, digital image analysis.

\section{Introduction}

Self-compacted concrete (SCC) has a tendency to segregate due to the high content of fine particles and less coarse aggregate volume in their composition. Increased flowability of the concrete mixture can cause problems with constituent materials stability and successful application of the SCC technology. It has been derived (Panesar \& Shindman, 2012) that SCC due to its particular plastic property is much more susceptible to stability problems than conventionally consolidated concrete. Furthermore, they showed that the use of high-quality ingredients and maintaining their right proportions does not guarantee good segregation resistance. Unstable structure of constituents has a negative impact on the physical properties and durability of SCC concrete.

A comprehensive report by American researchers (ACI Committee 238, 2008) and report of RILEM TC 188-CSC "Casting of self compacting concrete" (Skarendahl \& Billberg, 2006) showed that the stability of concrete mix constituents is the most important property that determines the applicability of self-compacting concrete. The stability of concrete mix ingredients often referred to segregation resistance is described as the ability to preserve a homogeneous distribution of concrete mix ingredients during casting the concrete mixture in the formwork (dynamic stability) and after this process (static stability). Self-compacted concretes are usually exposed to two forms of segregation: aggregate segregation and sedimentation.

Segregation of the SCC mix can result in dramatic effects in reinforced concrete structures (Daczko, 2012; Safawi, Iwaki, \& Miura, 2004, 2005). The segregation tendency in the vibration of high fluidity concrete according to Bui, Montgomery, Hinczak, and Turner (2002), segregation may lead to nonuniform results of compressive strength tests, which is confirmed by experience (Zhu, Gibbs, \& Bartos, 2001; Swedish Concrete Association, 2002). According to Panesar and Shindman (2012), apart from inhomogeneity of aggregate distribution in concrete, instability causes a weakening of the contact zone between aggregate and cement paste and can affect the bond behavior of concrete and steel reinforcement. The self-compacting concrete mixtures contain a higher volume of cement paste, which makes them more susceptible to shrinkage cracking than traditional concretes (Szwabowski, 2004; Szwabowski \& Gołaszewski, 2010). The bottom layer of the coarse aggregate has a tendency to settle down and leaves the mortar and cement paste in the upper layer. The inhomogeneous distribution of aggregate in the SCC mixture has an impact on the aggregate-paste zone. The poor bond behavior and consequences of increased shrink-

(C) 2019 Authors. Published by VGTU Press. This is an open-access article distributed under the terms of the Creative Commons Attribution (http://creativecommons.org/licenses/by/4.0/) License, which permits unrestricted use, distribution, and reproduction in any medium, provided the original author and source are credited. 
age may occur selectively or simultaneously. These pathologies may increase the vulnerability of reinforced concrete structures to microcracking, which is most important while ensuring long term durability of these structures.

Many test methods can be used to directly or indirectly measure segregation. The researchers have studied segregation by focusing on concrete mix testing. Other investigations describe studies conducted on the fresh mix and hardened concrete including on-site experiments.

A comprehensive review on the effects of constituents of fresh concrete, including cement, supplementary cementitious materials (fly ash, ground blast furnace slag, and silica fume), limestone powder, coarse and fine aggregates, and chemical admixtures (superplasticizer, viscosity modifying agent and air-entraining agent) on the rheological properties have been desribed by Wang, Kong, Sun, and Shui (2013), Jiao et al. (2017), Kovler and Roussel (2011), and Ponikiewski and Gołaszewski (2012). The tests results reported by Rols, A. Jean, and P. Jean (1999) was also conducted on the concrete mixture. The segregation resistance of concrete has been measured using a cylindrical mold, divided into three portions of concrete mix from the top, middle, and bottom. A fresh concrete sample was washed out through a mesh screen and weighed. Authors reported, that there is no segregation behavior and coarse aggregates have uniform distribution if the percentage of coarse aggregates retained on the mesh, in each section is close to $32 \%$. Petrou (Petrou, Harries, Gadala-Maria, \& Kolli, 2000) present a unique experimental method using scintillation camera to observe and record settlement of radioactively - tagged - aggregate in mortar and concrete in real time. The achieved images were used to study the rheological properties of the vibrated concrete mix. Authors presented that in ordinary concrete without vibration, typically-sized aggregate does not settle in mortar or concrete, settlement stops immediately after vibration is terminated. A tendency for aggregate to migrate horizontally toward the vibrator was observed.

Estimating the segregation of concrete based on mixture design and vibratory energy was described by Navarrete and Lopez $(2016,2017)$. Authors proposed five degrees to evaluate the segregation of concrete. The model for segregation based on mixture design and vibratory energy has been shown. The major conlusions obtained in this research was: segregation trend is mainly related to mixture design rather than to vibration process and aggregate properties are the factors that most affect the vibrated concrete stability.

Zhu (Zhu et al., 2001) presented an approach based on the rebound hammer and pull-out method for the analysis of concrete segregation in practical construction columns and beams. The results of the SCC concrete and ordinary concrete tests were compared. The results indicated that there were not significant differences in uniformity of in situ properties between the SCC mixes and the corresponding well compacted conventional mixes. Bui (Bui et al., 2002) presented the testing method for rapid assessment of segregation resistance of SCC in the vertical and horizontal direction using the original apparatus. The test results showed that the method can reduce testing time and laboratory work, developing apparatus, and method are useful in rapidly assessing the segregation resistance of SCC in both vertical and horizontal directions. A method to quantitate the segregation phenomena using geoendoscopy and automatic image processing techniques was presented by Breul, Geoffray, and Haddani (2008). The research results showed that the method can be successfully applied to assess the segregation resistance of SCC on site. The comprehensive research (Panesar \& Shindman, 2012) examined segregation performance measured on SCC mix by column method, visual stability index and V-funnel test. The research results achieved on fresh SCC mix was correlated to physical properties of hardened concrete. It has been shown that SCC cast with quality materials and mix proportions in accordance with current guidelines may still be vulnerable to poor segregation resistance which can result in adverse effects on surface transport properties and durability performance.

The paper presents the proposal to use the original attachment and digital image analysis procedure to study the fine and coarse aggregate segregation phenomena in hardened self-compacted concrete. The authors approach based on the specialized sample lighting method allows distinguishing of the aggregate grains from the concrete surface image and their analysis. The method can be used for testing samples made in the laboratory and samples taken from the structure.

\section{Materials and mix design}

One SCC concrete mixture with the composition shown in Table 1 was investigated in this research. The concrete was made of the following components.:

- The Portland Cement type I $42.5 \mathrm{~N}$ SR3/NA.

- The limestone powder as a mineral addition ( $25 \%$ of cement by mass).

- Natural sand 0_2 $\mathrm{mm}$.

- Coarse limestone aggregate $\left(2 \_8 \mathrm{~mm}\right.$ and $\left.8 \_16 \mathrm{~mm}\right)$.

- The polycarboxylate superplasticizer.

The concrete mix used in the research was designed based on the author's experience and in accordance with the guidelines (SCC European Project Group, 2005). The total content of fines in the concrete is $545 \mathrm{~kg} / \mathrm{m}^{3}$ and water to cement ratio of 0.40 . The total content of sand in concrete mixture is $767 \mathrm{~kg} / \mathrm{m}^{3}$. The total content of limestone coarse aggregate for concrete mix is $938 \mathrm{~kg} / \mathrm{m}^{3}$. The polycarboxylate superplastcizer dosage is $1 \%$ of cement and limestone fines by mass to intentionally obtain concrete with poor segregation resistance. The total aggregate volume 
in concrete mix is $\mathrm{V}_{\mathrm{T}}=63.7 \%$, which consists of sand volume $\mathrm{V}_{\mathrm{S}}=29.0 \%$ and total coarse crushed limestone volume $\mathrm{V}_{\mathrm{L}}=34.7 \%$. Mix proportions are reported in Table 1 .

Table 1. Mix design proportions

\begin{tabular}{|l|c|c|}
\hline \multicolumn{1}{|c|}{ Constituent } & Amount $\left[\mathrm{kg} / \mathrm{m}^{3}\right]$ & Volume of constituents [\%] \\
\hline Water & 178 & - \\
\cline { 1 - 2 } Cement & 436 & \\
\hline Limestone fines & 109 & 29.0 \\
\hline Sand & 767 & 34.7 \\
\hline Limestone 2-8 & 469 & \\
\hline Limestone 8-16 & 469 & \\
\hline Superplasticizer & 5.4 & \\
\cline { 1 - 2 } Specific gravity of mix & 2430 &
\end{tabular}

The volume of the batch was $18 \mathrm{dm}^{3}$, the concrete mixture was prepared in a $30 \mathrm{dm}^{3}$ capacity pan mixer. The mixing sequence was conducted in according to (SCC European Project Group, 2005) and author's common practice in the following order:

1. The sand, coarse aggregate and $85 \%$ of mixing water were mixed for ca. $60 \mathrm{~s}$.

2. Portland cement and limestone fines were added and mixed for 3 min with the remaining water being added while the mixer was running.

3. The total amount of superplasticizer was added and the concrete was mixed for an additional $7 \mathrm{~min}$.

A fresh concrete mix tests: slump-flow test and specific gravity were performed after completing the mixing sequence. The specific gravity of concrete mixture was $2430 \mathrm{~kg} / \mathrm{m}^{3}$ and the slump-flow test was $700 \mathrm{~mm}$. In the next step set of three $150 / 300 \mathrm{~mm}$ cylinder forms were cast. All three cylinders were demolded at $24 \mathrm{~h}$ and were cured in water bath for 28 days at $20^{\circ} \mathrm{C}$ until testing. In the next step after curing all specimens were cut with a diamond saw lengthwise in the middle to obtain one $40 \mathrm{~mm}$ thick slab. The slab was divided into three equal parts to acquire complement specimens. A set of three plate samples: one from the top of cylinder, one from the center of cylinder and one from the bottom was selected from group of specimens and examined in digital image analysis procedure as shown in Figure 1. The top and the bottom samples were used for further testing.

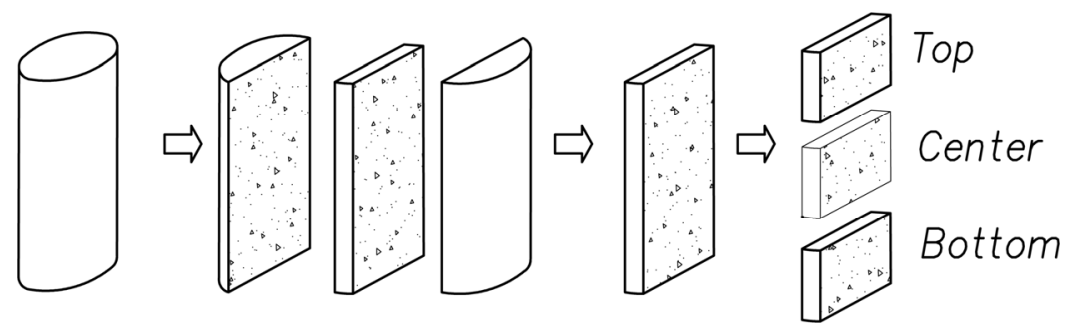

Figure 1. The procedure for preparing plate samples

\section{Digital image analysis procedure}

The examined plate samples were prepared with careful grinding and polishing process to perform smooth and flat surface, essential to create high quality sharp digital image. The concrete specimen surfaces of were captured using a professional equipment consisting of a stereoscopic microscope, a CCD camera, a cross table, and a PC with customized software to perform the specimen scanning and setup, image acquisition and numerical analysis. The original attachment mounted on the lens of the microscope is an additional accessory. The attachment is fitted with a focused light source placed in the vicinity of the optical axis of the lens (part of the vision field in the left eyepiece is obscured). The light rays are reflected from the specimen surface and are visible in the right-hand part of the field of vision in the objective lens. The image from this part is sent through the camera to the computer.

The unique procedure presented in this paper is based on information that sand and coarse aggregate grains on the image are much brighter than the cement paste that surrounds them. The grains, particularly the sand grains, have a dense structure and low porosity and reflect light rays better than the porous cement pastes producing scattered light. By making the paste darker with the use of phenolphthalein, the contrast between the aggregate and paste increases. Coarse aggregate grains have poorer reflectivity, appear less bright, have irregular edge shapes and require 
additional time for correcting the shape and infilling the grains. A series of colour photographs were stiched into a two large images (top and bottom image) of dimensions ca. $90 \times 70 \mathrm{~mm}$ covering a considerable area of the each sample (up to $63 \mathrm{~cm}^{2}$ ). Single photographs with sizes $640 \times 490$ pixels were taken using the calibration of $6.7510 \mu \mathrm{m} / \mathrm{px}$. The size of each image was about $230 \mathrm{MB}$. Analysis of images larger than $230 \mathrm{MB}$ creates great difficulties in computer processing.

Figure $2 \mathrm{~A}$ shows the image of a sample illuminated using the originally developed attachment. Figure $2 \mathrm{~B}$ shows the same area with a distinguished fraction of the coarse aggregate and sand.
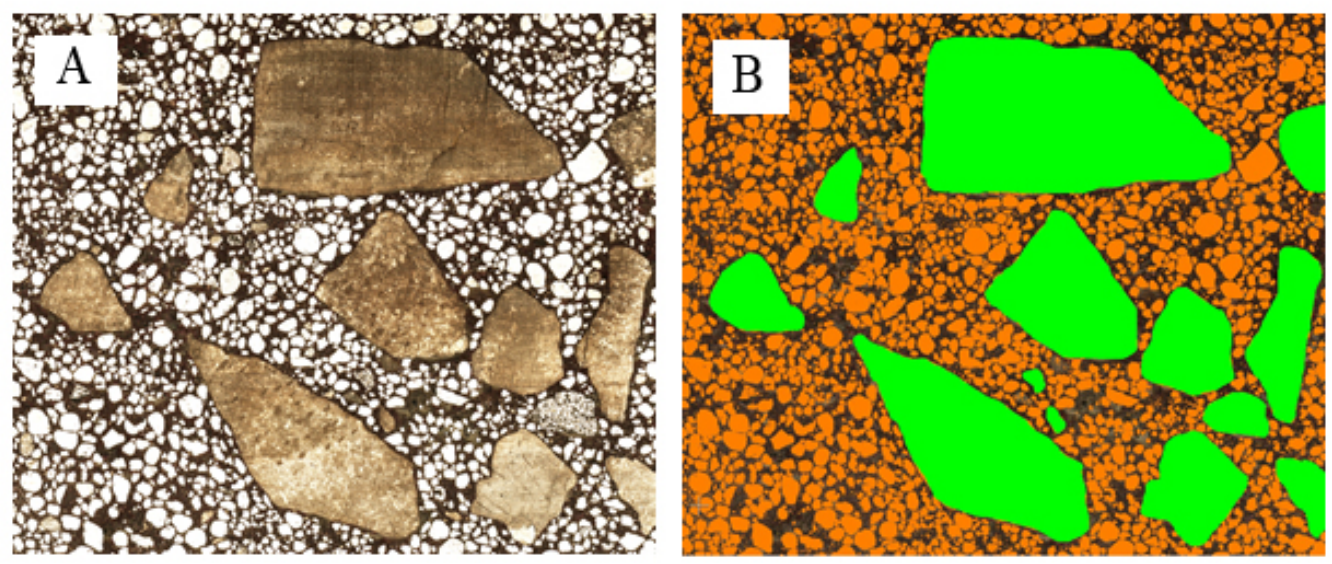

Figure 2. The excerpts of image acquisition. A - image achieved using original attachment (sand particles are distinguished in white colour), B - image processed in binary mode (sand and coarse aggregates are distinguished in red and green colour)

\section{Results and discusion}

The images of the top and bottom samples are presented in Figure 3. The images taken from two samples cut from the top and bottom of the cylinder were analyzed. The $6 \mathrm{~mm}$ thick upper layer which consists of cement paste, has been ignored in the analysis. The remaining part of the image surface of the upper sample was divided into 5 equal parts (Top AREA 1-5) with dimensions of $12.8 \mathrm{~mm}$ by $90 \mathrm{~mm}$. The total content of sand and coarse aggregate was calculated for each top area and for complete image of top sample.

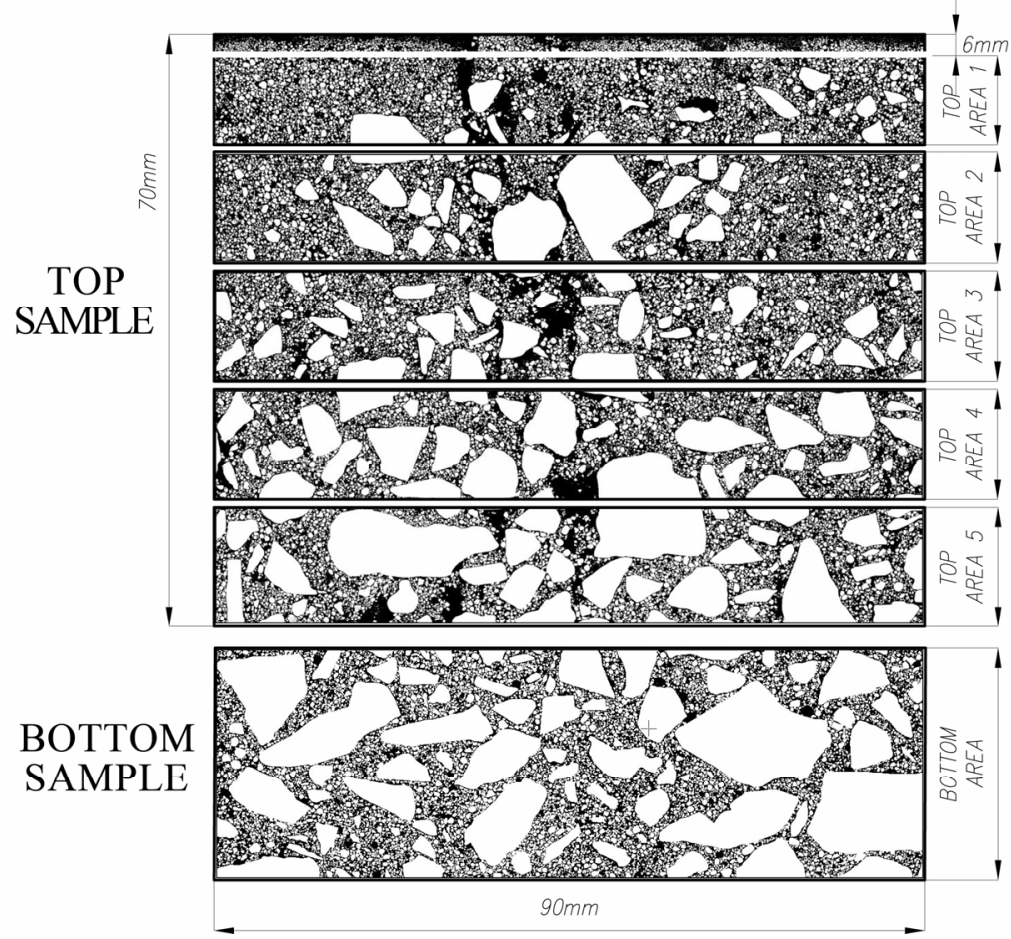

Figure 3. The digital image of plate specimen divided by areas of measurements 
Wawrzeńczyk, J.; Molendowska, A.; Kłak, A. 2019. Quantitative assessment of aggregate segregation of hardened self compacted concrete based on $2 D$ image analysis

Table 2. Microscopic measurement results

\begin{tabular}{|c|c|c|c|c|c|c|c|c|}
\hline \multirow{3}{*}{ Constituents } & \multirow{3}{*}{$\begin{array}{c}\text { Total } \\
\text { volume from } \\
\text { composition } \\
{[\%]}\end{array}$} & \multirow{3}{*}{$\begin{array}{c}\text { Plate from the bottom } \\
\text { Total volume } \\
{[\%]}\end{array}$} & \multicolumn{6}{|c|}{ Plate from the top } \\
\hline & & & \multirow{2}{*}{$\begin{array}{c}\text { Total volume } \\
{[\%]}\end{array}$} & \multicolumn{5}{|c|}{ Area of volume measurements [\%] } \\
\hline & & & & $\begin{array}{c}\text { Top area } \\
1\end{array}$ & $\begin{array}{c}\text { Top area } \\
2\end{array}$ & $\begin{array}{c}\text { Top area } \\
3\end{array}$ & $\begin{array}{c}\text { Top area } \\
4\end{array}$ & $\begin{array}{c}\text { Top area } \\
5\end{array}$ \\
\hline Sand & 29.0 & 26.12 & 26.26 & 33.75 & 29.58 & 30.27 & 21.6 & 18.86 \\
\hline Coarse aggregate & 34.7 & 47.35 & 32.61 & 10.21 & 29.58 & 27.11 & 46.22 & 50.61 \\
\hline Total aggregate & 63.7 & 73.47 & 58.87 & 43.95 & 59.16 & 57.38 & 67.82 & 69.44 \\
\hline
\end{tabular}

The better uniform distribution of constituents was observed in sample cut from the bottom of the cylinder. The total content of sand and coarse aggregate in the bottom sample with dimensions of $70 \times 90 \mathrm{~mm}$ was determined. The Figure 3 shows only a fragment of this area for comparison.

Based on the analysis of the top sample, it was found that the total sand content was $26.26 \%$ and the coarse aggregate was 32.61\%. The results of the research are presented in Table 2 and in Figure 4 . In the analysis of the top sample image, a significant difference was found in the content of sand and coarse aggregate (on the analyzed measurement areas). In the first area, the sand content is the highest (33.75\%) and the content of coarse aggregate is the lowest $(10.21 \%)$. Increasing the depth of the measurement areas in relation to the upper surface of the cylinder, the sand content decreases and the coarse aggregate increases. For Area 2 and Area 3, the sand content is 29.58 and $30.27 \%$ respectively, and the coarse aggregate $29.58 \%$ and $27.11 \%$. For the two deepest areas of the upper sample (Area 4 and Area 5), the sand content is 21.60 and $18.86 \%$ respectively, and the coarse aggregate 46.22 and $50.61 \%$. $47.35 \%$.

The bottom sample surface analysis showed that the total sand content was $26.12 \%$ and the coarse aggregate

The test results obtained from the image analysis were compared with the aggregate content taken from the composition of the tested concrete. The sand content from the composition of the concrete mix was $26.0 \%$ and the coarse aggregate $34.7 \%$. The test results indicate a large heterogeneity of the concrete constituents.

Based on the test results analysis, it can be concluded that the application of a simple microscopic analysis method with the use of the originally developed attachment gives the possibility of an accurate analysis of the sand and coarse aggregate in different concrete layers. This method provides further possibilities of analyzing the concrete composition reconstruction and estimating the concrete properties depending on the proportion of its components.

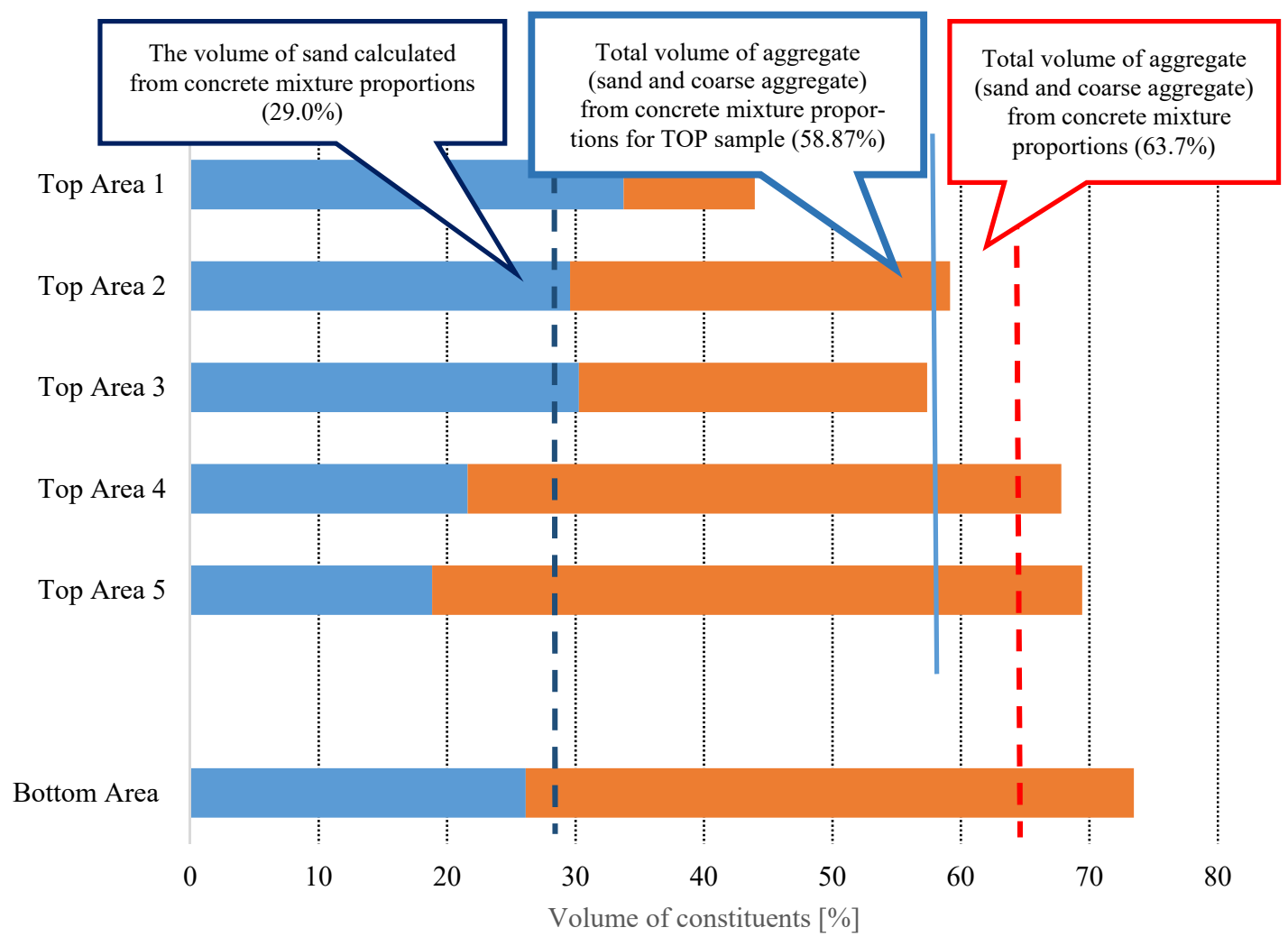

Figure 4. The volume of sand and coarse aggregate in top and bottom samples 


\section{Conclusions}

The following concluding remarks have been drawn from the overall analysis:

1. The use of a simple original attachment mounted on the lens of the microscope set enables to distinguish the aggregate particles in concrete. The sample preparatory work consisting of careful grinding and polishing of the specimen is very important.

2. Further development of this method allows determining the concrete composition in different layers, which would give the opportunity to evaluate the properties of concrete.

3. The application of the unique method and original attachment gives the possibility to observe many concrete structure pathologies including bleeding channels or substantial voids formed under the thick aggregate grains.

4. This method could find the application for testing samples taken from the structure.

\section{References}

ACI Committee 238. (2008). Report on measurements of workability and rheology of fresh concrete. Farmington Hills.

Breul, P., Geoffray, J. M., \& Haddani, Y. (2008). On site concrete segregation estimation using image analysis. Journal of Advanced Concrete Technology, 6(1), 1-10. https://doi.org/10.3151/jact.6.171

Bui, V. K., Montgomery, D., Hinczak, I., \& Turner, K. (2002). Rapid testing method for segregation resistance of self compacting concrete. Cement and Concrete Research, 32, 1489-1496. https://doi.org/10.1016/S0008-8846(02)00811-6

Daczko, J. A. (2012). Self-consolidating concrete: Applying what we know. CRC Press. https://doi.org/10.1201/b11721

Jiao, D., Shi, C., Yuan, Q., An, X., Liu, Y., \& Li, H. (2017). Effect of constituents on rheological properties of fresh concrete - A review. Cement and Concrete Composites, 83, 146-159. https://doi.org/10.1016/j.cemconcomp.2017.07.016

Kovler, K., \& Roussel, N. (2011). Properties of fresh and hardened concrete. Cement and Concrete Research, 41, 775-792. https://doi.org/10.1016/j.cemconres.2011.03.009

Navarrete, I., \& Lopez, M. (2016). Estimating the segregation of concrete based on mixture design and vibratory Energy. Construction and Building Materials, 122, 384-390. https://doi.org/10.1016/j.conbuildmat.2016.06.066

Navarrete, I., \& Lopez, M. (2017). Understanding the relationship between the segregation of concrete and coarse aggregate density and size. Construction and Building Materials, 149, 741-748. https://doi.org/10.1016/j.conbuildmat.2017.05.185

Panesar, D. K., \& Shindman, B. (2012). The effect of segregation on transport and durability properties of self consolidating concrete. Cement and Concrete Research, 42, 252-264. https://doi.org/10.1016/j.cemconres.2011.09.011

Petrou, M. F., Harries, K. A., Gadala-Maria, F., \& Kolli, V. A. (2000). A unique experimental method for monitoring aggregate settlement in concrete. Cement and Concrete Research, 30, 809-816. https://doi.org/10.1016/S0008-8846(00)00223-4

Ponikiewski, T., \& Gołaszewski, J. (2012). The self - compacting properties of concrete mixture of cement with calcareous fly ash addition. Cement Wapno Beton, 4, 233-242.

Rols, S., Jean, A., \& Jean, P. (1999). Effects of different viscosity agents on the properties of self-levelling concrete. Cement and Concrete Research, 29, 261-266. https://doi.org/10.1016/S0008-8846(98)00095-7

Safawi, M. I., Iwaki, I., \& Miura, T. (2004). The segregation tendency in the vibration of high fluidity concrete. Cement and Concrete Research, 34, 219-226. https://doi.org/10.1016/S0008-8846(03)00249-7

Safawi, M. I., Iwaki, I., \& Miura, T. (2005). A study on the applicability of vibration in fresh high fluidity concrete. Cement and Concrete Research, 35, 1834-1845. https://doi.org/10.1016/j.cemconres.2004.10.031

SCC European Project Group. (2005). The European guidelines for self-compacting concrete. Specification, production and use. Retrieved from https://www.theconcreteinitiative.eu/images/ECP_Documents/EuropeanGuidelinesSelfCompactingConcrete.pdf

Skarendahl, A., \& Billberg, P. (2006). Final report of RILEM TC 188-CSC 'Casting of self compacting concrete'. Materials and Structures, 39(10), 937-954. https://doi.org/10.1617/s11527-006-9186-9

Swedish Concrete Association. (2002). Self compacting concrete - recommendations for use (Concrete Report No 10).

Szwabowski, J., \& Gołaszewski, J. (2010). Technologia betonu samozagęszczalnego. Polski Cement.

Szwabowski, J. (2004). Reologia a urabialność betonu samozagęszczalnego. Cement Wapno Beton, 1, 14-19.

Wang, G., Kong, Y., Sun, T., \& Shui, Z. (2013). Effect of water - binder ratio and fly ash on the homogeneity of concrete. Construction and Building Materials, 38, 1129-1134. https://doi.org/10.1016/j.conbuildmat.2012.09.027

Zhu, W., Gibbs, J. C., \& Bartos, P. J. M. (2001). Uniformity of in situ properties of self-compacting concrete in full scale structural elements. Cement and Concrete Composites, 23, 56-67. https://doi.org/10.1016/S0958-9465(00)00053-6 